\title{
The Impact of Birth Order on Behavior in Contact Team
}

\section{Sports: Evidence of Rugby Teams*}

\author{
Fernando Delbianco ${ }^{\dagger 1}$, Federico Fioravanti ${ }^{\ddagger 1}$, and Fernando Tohmé ${ }^{\S 1}$ \\ ${ }^{1}$ INMABB, Universidad Nacional del Sur, Bahía Blanca, Argentina
}

\begin{abstract}
Several studies have shown that birth order and the sex of siblings may have an influence on individual behavioral traits. In particular, it has been found that second brothers (of older male siblings) tend to have more disciplinary problems. If this is the case, this should also be shown in contact sports. To assess this hypothesis we use a dataset from the South Rugby Union (URS) from the region of Bahía Blanca, Argentina, and information obtained by surveying more than four hundred players of that league. We find a statistically significant positive relation between being a second-born male rugby player with an older male brother and the number of yellow cards received.
\end{abstract} Keywords: Birth Order; Behavior; Contact Sports; Rugby.

\section{Introduction}

At the beginning of the $20^{\text {th }}$ century, Alfred Adler suggested that birth order influences personality. Adler (1928) believed that the firstborn would enjoy the full attention of the new parents until the arrival of a new child, that would cause him a feeling of "dethronement". He considered that the firstborn would be the most likely to be neurotic, dutiful and sometimes conservative. He also found that lastborn siblings are more ambitious, while middle children are characterized by emotional stability, as a result of what he considered to be the "optimal" position in the family.

${ }^{*}$ The authors would like to thank two anonymous referees and the Editor, whose suggestions helped to improve the original manuscript. We would also like to thank Martín Aspiroz, URS President, Juan Vigier, URS Referee Manager and all the URS staff, for their selfless help.

†fernando.delbianco@uns.edu.ar

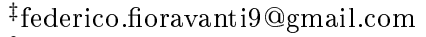

§tohme@criba.edu.ar 
Since then there have been numerous studies on birth order effects, both addressing or refuting Adler's claims. A study by Howart (1980) of 142 male and 170 female undergraduates found significant relationships of low anxiety and higher ego in firstborns. On the contrary, Damian and Roberts (2015a) in a study which included more than 370,000 high school students, concluded that the importance of birth order in shaping personality is generally exaggerated.

The debate has not abated. Black et al. (2018) show that firstborn children are more likely to become managers and fill positions requiring leadership and social ability as well as Big Five personality traits. Esposito et al.(2020) find that the birth order has a negative effect on the educational outcomes in Mexico, and furthermore, that the advantage of firstborns increases if they are male, in particular when the other siblings are female. Birth order is, thus, a seemingly relevant factor for the explanation of human behavior, although its actual relevance is still under discussion.

In this paper we take up from a recent study, based on the analysis of large databases on the life records of individuals in Florida and Denmark, showing that the being a second-born male child has an impact on delinquent behavior (Breining et al. 2020). The evidence indicates that males with an older brother tend to engage in more unruly and undutiful acts. We speculate that such behavior should be evidenced in the specific context of contact sports. Players that are second brothers should exhibit, in average, a large tendency to incur offenses. If so, those players should exhibit a larger record of yellow and red cards.

To evaluate this claim we use data on more than 400 male players of the different teams that play in the South Rugby Union (Unión de Rugby del Sur - URS), Argentina. We use information drawn from the records of the 2019 season of the local and regional championships as well as from a questionnaire asking information about the position of the players in the birth order of their families.

Based on this evidence we show that, indeed, it is the case that second born male players with male older brother, tend to commit a statistically significant larger number of offenses.

The plan of this article is as follows. In Section 2 we briefly discuss the literature on the influence of birth order on behavior and we describe the essential features of rugby that are relevant for this study. In Section 3 we introduce the database on which we run our analysis and describe how it was collected. Section 4 presents the descriptive statistics of the research variables. Section 5 describes the methodology used while Section 6 presents its results. Finally, Section 7 concludes. 


\section{Birth order, behavior and sports}

The relevance of birth order as a psychological variable has been discussed for decades, but no definite impact on behavioral traits were found at the early stage of those investigations. So for instance, while firstborns were shown to exhibit higher levels of conformity and need for achievement (Forer, 1977), other relevant variables that could also explain this were not explored. Reviews by Ernst and Angst (1983) and Dunn and Plomin (1990) found little reliable evidence of this relations: "[birth] order does not appear to be a very strong influence in molding personality in a definable way" (Ernst and Angst 1983). Damian and Roberts (2015b), in their PNAS paper, claimed that the study conducted by Rohrer et al (2015), has finally put an end to the debate and conclude that birth order has no effects on personality traits. ${ }^{1}$

In a very influential book, Sulloway (1996) acknowledged that even if birth order effects could be subtle, they could be detected in very large samples. While his results were controversial, this opened the door for further studies on issues like the influence of birth order on early smoking (Bard and Rodgers 2006), competitive preferences (Okudaira et al. 2015) or on intelligence (Damian and Roberts 2015a). A long term study showed that birth order has an impact on differences in health and educational attainment of older and younger siblings (Barclay and Kolk 2018).

A common finding in those studies is a slight but statistically significant difference between first and laterborns. In particular, the latter tend to exhibit "worse" results than firstborns. ${ }^{2}$ Breining et al. (2020) carried out the largest study, using lifelong data from people of diverse cultural and ethnic backgrounds in Denmark $(N>400,000)$ and the state of Florida $(N>1,000,000)$, detecting that second brothers tend to exhibit a higher level of delinquent behavior. One of the main possible explanations is that the difference resides in the time devoted by parents to their firstborn children in comparison to that spent in their younger siblings. Interestingly, this does not seem to be as marked when either the older or the youngest child is a girl.

This leads us to the immediate conclusion that this effect should manifest in contact sports, in which there are numerous opportunities for wrongdoing. While there are different sports in which this effect could be at play, in some of them (soccer, for instance), the impact of birth order may be difficult to isolate and be confounded by cultural and socio-economic differences, that may also lead to aggressive behavior (Miguel et al. 2008). ${ }^{3}$ To avoid those confusions we decided to study how this effect plays out in

\footnotetext{
${ }^{1}$ Rohrer et al (2015) analyzed a sample of size $N=5,240$ in the United States, $N=4,489$ in Great Britain and $N=10,457$ in Germany. They found a slight birth order effect on intelligence but no consistent evidence of effects on extroversion, emotional stability, agreeableness, conscientiousness or imagination.

${ }^{2}$ As for instance starting to smoke at an early stage; being overweight, etc.

${ }^{3}$ In their study, they find a strong relationship between the history of civil conflict in the home country of a player and his propensity to behave violently in the soccer field, as measured by yellow and red cards.
} 
a sport in which the background of the players is more culturally homogeneous and relatively prosperous. For this reason we have chosen rugby, a game played in Argentina by middle and upper-class people of European-influenced culture (Bautista Branz 2016).

In rugby, players are classified in two big groups, the forwards and the backs. Traditionally, the forwards are the players that seek to get the possession of the ball while the backs are the ones that score tries. Forwards are usually heavy players, with strength to dispute the ball, while backs are light players, with speed to score tries. The key features of a good rugby match are the fair contest for the ball and the continuity of the game. Every action that attempts against these two key features, the security of the players or the values of the game (integrity, discipline and respect) is punished. When an offense committed by a player is serious, a yellow or red card is shown to him. Every foul play like punching, kicking, spitting, etc, is usually penalized with a yellow or red card (penalizing actions against security and values). Another offense that is penalized with a card, is when a player or a team infringes the rules many times or when their infringement prevents the other team to score a try (penalizing actions against fair contest and continuity). Of these kind of infringements, some of them can be considered as caused by risk-taking behavior, because the action per se is not an infringement and depends on the outcome. ${ }^{4}$ A typical situation where many offenses occur is the breakdown. ${ }^{5}$ In a rugby game can happen from 100 to 150 breakdown situations and many players are involved in them, specially the forwards. That is why many of the offenses in a rugby game happen in this context. ${ }^{6}$

Therefore, a yellow or a red card indicates, in increasing degree, that a player has failed to act according to the values of the game and can be seen as a sign of unruly behavior (Romand and Pantaleón 2007). In some cases a yellow card indicates a risk taking behavior of that player, which is also an undutiful action.

The literature presents several studies on birth order and sports that are in line with our hypothesis. Nisbett (1968) showed that firstborns were less likely than laterborns to participate in three sports that he considered to be dangerous: football, soccer and rugby. Theroux (1993) conducted a study on more than 190,000 college freshmen in the United States and found that laterborns were more likely than firstborns to win a varsity letter in high school and also spend more time discussing about sports with their friends. She suggested that to counter the firstborn "academic progeniture", the laterborn cultivates athletic ability. This finding reflects the well-documented tendency of the firstborn to be the one occu-

\footnotetext{
${ }^{4}$ An example can be when a player tries to intercept a pass. If he gets the ball, the game continues; but if he touches it and the ball goes forward, an infraction is noted, which usually ends with the referee showing a yellow car to that player.

${ }^{5}$ The period of time after a tackle and during the ensuing ruck (a contest situation where two or more stand players dispute the ball).

${ }^{6}$ https : //www. world.rugby.
} 
pying the niche of the achievement oriented, studious sibling (Sulloway 2007).

A particularly relevant study is Sulloway and Zweigenhaft (2010). They conducted a meta-analysis of 24 studies relating birth order and participation in dangerous sports, finding that it is more probable that laterborns engage in them than firstborns. They also analyze (with a within-family design experiment) performance data on 700 brothers that played baseball in the US major leagues. Professional baseball presents a detailed statistical record and offers a variety of performance categories reflecting behavioral differences in skill, self-control, risk taking, and performance. They concluded that younger brothers were more likely to engage in the risky business of stealing bases.

Different mechanisms have been postulated as explanations for why laterborns may adopt more aggressive conduct or risk taking behavior. Becker $(1960,1973,1976)$ proposed a model that reconciles fertility and parental investment in children. The so called "quantity-quality trade off" states a negative correlation between the number of children and their parents income originating from the rising marginal cost of quality with respect to quantity.

Hotz and Pantano (2015) argue that parents, intending to send signals to younger children, may apply more intense monitoring and discipline on the oldest child. Sulloway (1996) speculates that, in order to gain parental attention, first born children may be more likely to emulate and obey their parents. Because of this, younger siblings have to consider unconventional alternatives in order to gain parental favor. Puffer and Serrano (1973) have shown that laterborns generally have higher mortality rate in various Latin American countries. This has also been documented in developed countries (Hertwig et al. 2002). This leads to laterborns to incur in more risks, as the costs of risk taking are reduced whenever life expectancy is reduced (Daly and Wilson 1988)(Wang et al. 2009). A final possible explanation is that laterborns may assume greater risks to establish alliances with peers as part of a strategy to compensate for receiving less parental investment (Salmon and Daly 1998)(Sulloway 1996)(Wang et al. 2009).

\section{Data}

The data for this research has been collected from the 2019 records (i.e. data on a single year) of the South Rugby Union (URS) of Argentina and from the answers to a survey conducted by the URS on the family structure and education of the players. We will discuss these two sources and the information extracted from them.

The URS provided us the following data about the players: full name, club membership, date of birth, 
height, weight, position on field and yellow and red cards record from the 2019 season. This information was later matched to the responses given by each player to a survey ${ }^{7}$. The questions asked to them gave us the following additional information: years playing rugby, educational attainment, birth order and siblings gender.

The URS is a medium level amateur league, where the only requisite for any one interested in playing is the willingness to train and agree to the rules. This give us the opportunity to conduct the survey in an environment where every respondent has sought and found a team in which to play. So, no player has been left aside or discarded by his team because of the quality of his skills. It is also an environment where players share, in general, a homogeneous cultural, social and economical background. ${ }^{8}$

The survey was sent to the coaches of the teams, and given by them to their players. Answering it was not mandatory, and the devolution rate was of around $60 \%$ (415 completed surveys out of 698 senior players). ${ }^{9}$ The respondents were all male amateur rugby players of ages $18+$ playing in the local and regional tournaments recorded in the URS database. These players belonged to 21 different clubs from the South of the province of Buenos Aires, the East of La Pampa and the North of Río Negro.

We decided to not consider the answers of a few younger players under 18. The main reasons for this decision are two. First, most coaches were reluctant to send out the questionnaire to underage players, and thus we did not get enough useful data. The second reason is that in the junior competitions in which younger players participate, the refereeing is not strict. In these matches, even if a player may deserve a yellow or red card, he may not be shown one. So, referees do not respond with the same severity to similar actions in junior and senior games. For example, in first division matches, repeated infringements are shown a yellow card, while in junior level games the same situation will usually lead the referee to give a talk to the players as to convince them to change their behavior. ${ }^{10} 11$

\section{Descriptive statistics}

In Table 1 we can see the main statistical description obtained by combining the URS database from the 2019 season with the survey answers. ${ }^{12}$ We use two main indicator variables to answer our research

\footnotetext{
${ }^{7}$ The survey questionnaire can be found in Appendix 1.

${ }^{8}$ This information was obtained by asking the URS president, Martín Azpiroz. The questions and his answers can be found in Appendix 2.

${ }^{9}$ We only consider the complete surveys, i.e., the ones with all the questions answered in the right format.

${ }^{10}$ This information was obtained by asking the URS Referee Manager, Juan Vigier. The questions and his answers can be found in Appendix 2.

${ }^{11}$ The records confirm this: 524 cards were given in 288 first division games (1.81 cards per game), while only 187 cards in 970 youth division games (0.19 cards per game).

${ }^{12}$ We used Gretl (http://gretl.sourceforge.net/) to run the statistical analyses in this article.
} 
question, Code 1 and Code2. The first one has value 1 if the player is a second born boy with an older male brother and 0 otherwise. Code2 is also a dummy variable indicating whether or not a player is a second born boy but with an older sister.

We decided to consider only yellow cards because very few red cards are recorded in the database, as seen in the 0.0169 mean value of the red cards variable in Table $1 .{ }^{13}$ The database is further completed with contextual information, such as club membership, educational attainment (incomplete secondary education, complete secondary school, incomplete college or completed tertiary education), height, weight and position (forward or back). This extra information is used to define different indicator variables for control purposes in our regressions.

Table 1: Summary statistics

\begin{tabular}{lcccccc} 
Variable & Mean & Median & Std. Dev & Min & Max & Observations \\
\hline \hline Age & 25.9 & 25.0 & 6.47 & 18.0 & 50.0 & 415 \\
Yellow Cards & 0.667 & 0.000 & 1.06 & 0.000 & 8.00 & 415 \\
Red Cards & 0.0169 & 0.000 & 0.129 & 0.000 & 1.00 & 415 \\
Weight & 90.0 & 88.0 & 17.1 & 51.0 & 145.0 & 310 \\
Height & 1.77 & 1.78 & 0.0675 & 1.55 & 1.98 & 310 \\
Code 1 & 0.186 & 0.000 & 0.389 & 0.000 & 1.00 & 415 \\
Code 2 & 0.116 & 0.000 & 0.320 & 0.000 & 1.00 & 415 \\
\hline
\end{tabular}

We focus in this section on the variables that, as will be shown in the next section, are statistically relevant. That is, we will here give a description of the distribution of the number of yellow cards received, the dummy variables corresponding to birth order and the weight of players, as indicated in Table 1.

In Figure 1 we can see the distribution of the total number of yellow cards, i.e. the number of players with $0,1, \ldots$ up to 8 cards. The left panel corresponds to the players that are not second born boys $(\operatorname{Code} 1=$ Code $2=0$ ), while the middle one to those who are second born boys with an older brother $($ Code $1=1)$ and the right one to those who are second born boys with an older sister $($ Code $2=1)$.

We can see in the middle panel that the proportion of one and two yellow cards with respect to 0 cards, is much larger than in the cases of the left and the right panel. Furthermore, these two panels show similar distributions.

\footnotetext{
${ }^{13}$ For robustness purposes, we ran the same regressions with a slightly different dependent variable consisting of the sum of yellow and red cards. The results, reported in Table 8, are quite similar. This is not surprising, given the scarcity of red cards in the database (only 7 in total).
} 
An interesting collateral result is the relation between being a second born boy and the weight variable, as we can see in Figure 2. The middle panel corresponding to second born boy with an older brother (Code $1=1$ ), shows a higher median, more skewed to the right, in comparison to the bottom, not being a second born boy (Code $1=$ Code $2=0$ ) and top boxplot, being a second male child with an older sister $($ Code $2=1)$.

Figure 1: Number of yellow cards (x-axis) and number of cases in the database (y-axis).

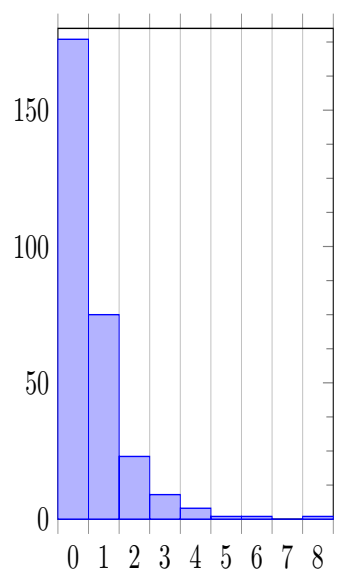

(a)

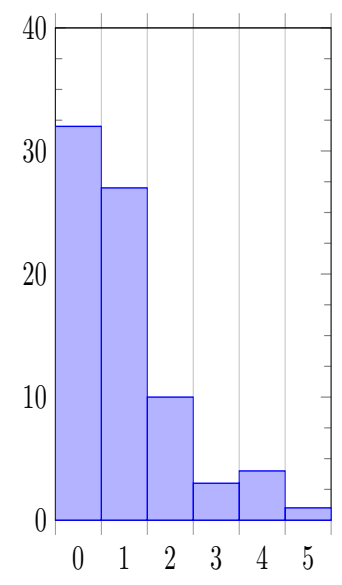

(b)

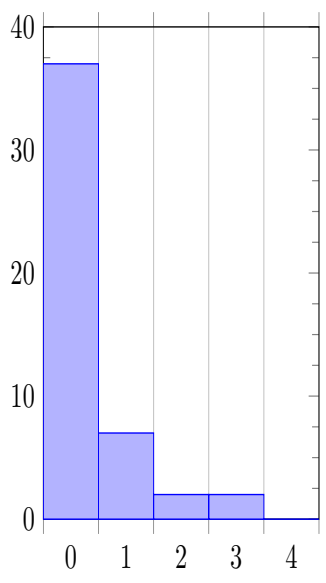

(c)

(a): not second born boy ; (b): second born boy with an older brother; (c): second born boy with an older sister

In Figure 2 we can see that the median weight corresponding to being a second born boy is larger (93 kilograms) than that of the other groups, with a wider inter-quartile range, indicating a larger dispersion.

We can see the relation between the number of Yellow Cards received by a player and his (declared) Weight in Figures $3 \mathrm{a}$ and $3 \mathrm{~b}$, indicating a positive relation between the weight of players and the number of yellow cards they receive, although at the largest weights (very few cases) this relation is lost.

Finally, we test for the variables of interest the differences between means, as reported in Table 2 . We can see, first, that there exists a significant difference between the mean of Yellow Cards for a second born boy with an older brother (an average of 1 card), and the 0.59 mean of the rest of the sample. The second test shows, despite the evidence of the boxplot for medians, that when we test the difference of means of Weight under Code $1=1$, against the rest of the sample, there are no significant differences. Finally, in the third test, we compare the mean weight of the players that did not get yellow cards with that of those who got at least 1 yellow card. The statistically significant difference is of almost 4 kilograms. 
Figure 2: Box Plot of Weight.

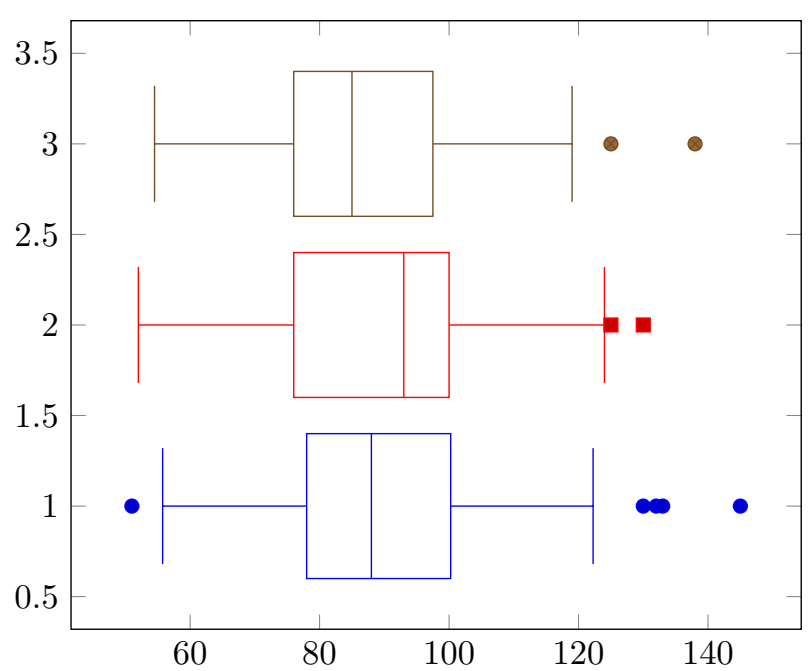

Note: top: second born boy with an older sister; middle: second born boy with an older brother; bottom: not a second born boy

Figure 3: Yellow cards and Weight

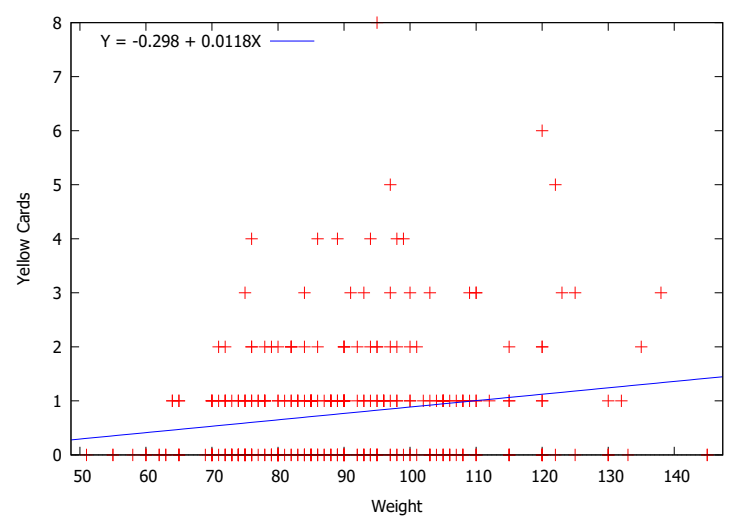

(a) Linear relation.

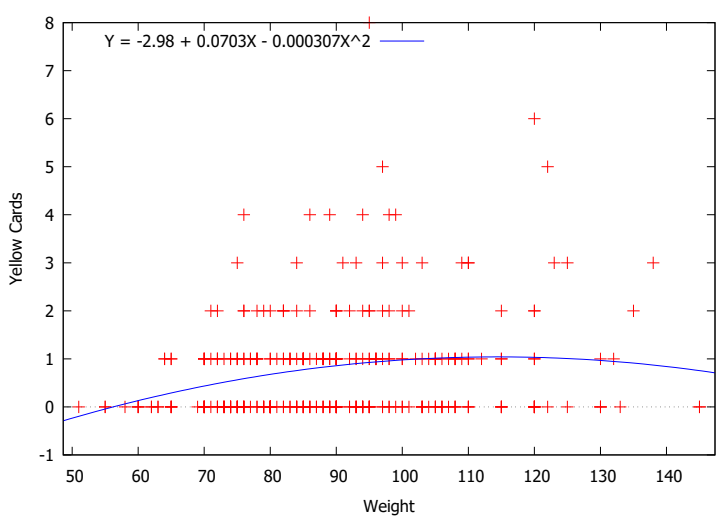

(b) Quadratic relation.

In the data set there are 15 pairs and 1 trio of brothers. Each of these family groups plays in the same team. In Table 3 we show the data on the number of yellow cards for them. The number of observations does not yield significant differences between second male brothers and the rest of them.

\section{$5 \quad$ Methodology}

Our main hypothesis, as indicated above can be stated as:

the number of yellow cards must be larger for Code 1 players.

In other words, we will test for the validity of the claim that second born males with an older brother 
Table 2: Mean tests

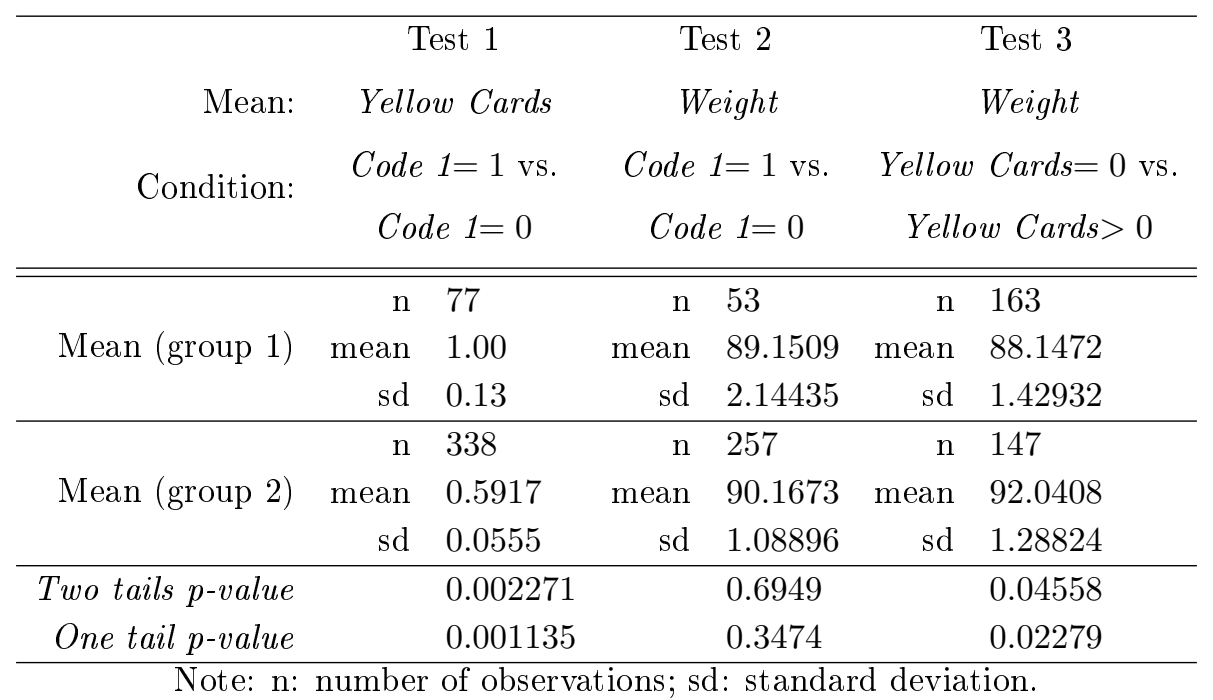

Table 3: Number of Yellow cards of brother's teammates by Code Variable

\begin{tabular}{ccc}
\hline Yellow Cards & Not second born boy with older brother & Second born boy with older brother \\
\hline 0 & 10 & 5 \\
1 & 3 & 2 \\
2 & 6 & 7 \\
\hline
\end{tabular}

will tend to commit more offenses. To evaluate this hypothesis we run a series of regressions of the form:

$$
\text { Yellow Cards } s_{i}=\beta_{0}+\beta_{1} \text { Code } 1_{i}+\beta_{2} \text { Code } 2_{i}+\Gamma \mathbf{x}_{i}+\epsilon_{i}
$$

in which our coefficients of interest are $\beta_{1}$ and $\beta_{2}$, varying a vector of control variables $\mathbf{x}$. Table 6 summarizes the results of these regressions.

Given that our dependent variable, Yellow Cards, is a counting variable, we will also take this particular feature into account, modeling the relation both as a Poisson regression and as a negative binomial regression. As pointed out by Orme (2009), Hilbe (2011) and Cameron and Trivedi (2013), it is intuitive to think that in the case of a counting variable $y$, it will follow a Poisson distributions:

$$
f\left(y_{i} \mid \mathbf{x}_{i}\right)=\frac{e^{-\mu_{i}} \mu_{i}^{y_{i}}}{y_{i} !}, \quad y_{i}=0,1,2, \ldots
$$

where the mean is expressed as follows:

$$
\mathrm{E}\left[y_{i} \mid \mathbf{x}_{i}\right]=\mu_{i}=\exp \left(\mathbf{x}_{i}^{\prime} \boldsymbol{\beta}\right)
$$


We adjust the observations to this distribution using a Quasi-Maximum Likelihood estimation with robust standard errors, in the form of:

$$
\mathrm{V}_{\mathrm{RS}}\left[\hat{\boldsymbol{\beta}}_{\mathrm{P}}\right]=\left(\sum_{i=1}^{n} \mu_{i} \mathbf{x}_{i} \mathbf{x}_{i}^{\prime}\right)^{-1}\left(\sum_{i=1}^{n}\left(y_{i}-\mu_{i}\right)^{2} \mathbf{x}_{i} \mathbf{x}_{i}^{\prime}\right)\left(\sum_{i=1}^{n} \mu_{i} \mathbf{x}_{i} \mathbf{x}_{i}^{\prime}\right)^{-1}
$$

where $\left(y_{i}-\mu_{i}\right)^{2}=\omega_{i}$, is the weighing factor.

An important assumption in the case of Poisson distributions is that the variance equals the mean. A $\chi^{2}$ test yields that the assumption of equality between the mean and the variance is not valid. Thus, we have to drop the assumption of a single parameter, resorting to a negative binomial regression, by including a parameter of overdispersion, $\alpha$, where $\alpha>0$ (in a Poisson model, $\alpha=0$ ).

Given $\alpha$, the term weighting the variance and covariance matrix is:

$$
\omega_{i}=\mu_{i}+\alpha \mu_{i}^{p}
$$

If $p=1$ the model is called Negative Binomial 1 (NB1), and if $p=2$, Negative Binomial 2 (NB2). Since we do not have an a priori model of the generation of yellow cards we just take the results obtained up to this point and choose to work with the NB2 and NB1 models and compare the AIC information criteria. ${ }^{14}$ In the rightmost columns of Table 7 we report the general results with this last model, where:

$$
\mathrm{E}\left[\text { Yellow }_{i} \mid \mathbf{x}_{i}\right]=\exp \left(\beta_{0}+\beta_{1} \text { Code } 1_{i}+\beta_{2} \text { Code } 2_{i}+\beta_{3} \text { Weight }{ }_{i}\right)
$$

\section{Regression results}

In the first column of Table 6 we report the results of running the standard OLS with no controls. We can see that being the second male child with an older brother or the second male child with an older sister (Code 1 and Code 2) yield results that can be expected according to our hypothesis, positive and negative respectively. Not surprisingly, the Breush-Pagan test indicates the presence of heteroskedasticity (Non-constant Variance Score Test with $\chi^{2}=6.965588, p=0.0083092$ ), while a Cook-distance test reveals the presence of influential observations in the simple regression. Due to these evidence, we refined our analysis. We did so by applying two strategies: by considering White's robust errors and by clustering the variance and covariance matrices.

In columns $2-5$ of Table 6 we can see the robust error regression results, with different controls

\footnotetext{
${ }^{14} \mathrm{~A}$ non-linear specification of the $\omega_{i} \mathrm{~s}$ is better at capturing finer distinctions in the data.
} 
added. The main result in these cases is that Code 2 loses significance in columns 3 and 4 , but we find a significant and positive effect of the player's weight on the resulting number of yellow cards (although with a very small coefficient). Another variable that shows a significant effect is the Incomplete Secondary School dummy.

The last two columns show the results of running the regressions with a clustered error, based on the variable indicating to which club the player belongs. This is in order to capture the intuition that teammates tend to show similar styles of play (sharing a common coach). The results were, again, the expected under the hypothesis.

The general results of the Poisson and Negative Binomial regressions can be seen in the appendix in Table 7 . Table 4 and Figures $4 \mathrm{a}$ and $4 \mathrm{~b}$ present the results of this model with our variables of interest.

Table 4: Negative Binomial Regression Results $(p=2)$

\begin{tabular}{lcccc} 
& Coefficient & Standard Deviation & $z$ & p-value \\
\hline \hline Constant & -1.80345 & 0.439240 & -4.106 & 0.0000 \\
Weight & 0.0162847 & 0.00468983 & 3.472 & 0.0005 \\
Code 1 & 0.409718 & 0.173700 & 2.359 & 0.0183 \\
Code 2 & -0.545480 & 0.295712 & -1.845 & 0.0651 \\
$\alpha$ & 0.540983 & 0.177833 & 3.042 & 0.0023 \\
\hline Observations & 310 & & & \\
AIC criteria & 736.9341 & & & \\
\multicolumn{4}{c}{ Note: Quasi-Maximum Likelihood Standard Errors. }
\end{tabular}

Figure 4: Yellow cards observed, predicted and residuals.

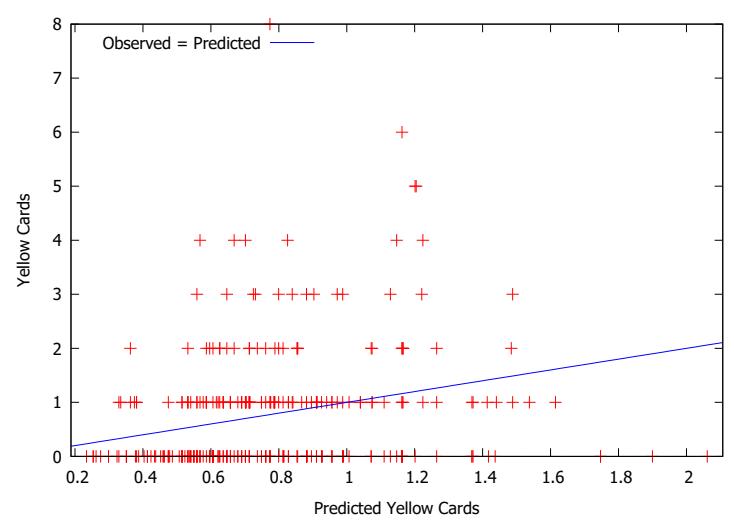

(a) Linear prediction.

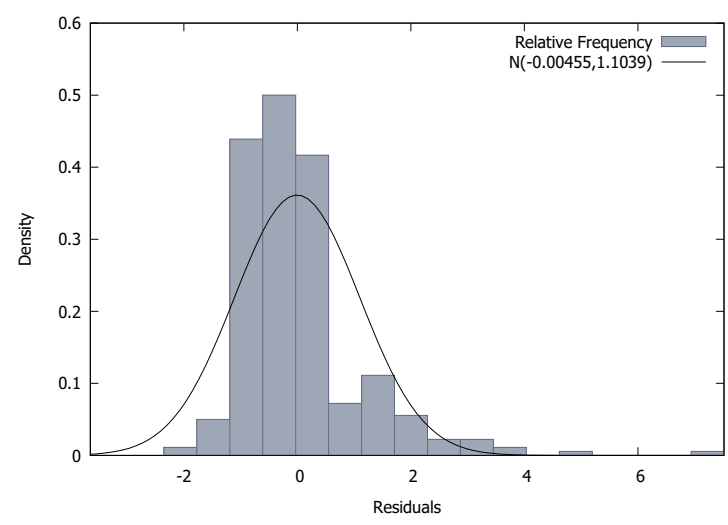

(b) Normality contrast.

We can see that being a second born boy with an older brother (Code 1), being a second born boy with an older sister (Code 2), Weight and the overdispersion coefficient $\alpha$ are all statistically significant. 
Figure 4a shows that the linear model leaves many actual values of Yellow Cards far from the predicted ones, resulting in Figure 4b, that indicates that most of the residuals are below the normal, being their distribution skewed to the right as a result of the overdispersion.

To ensure the robustness of our results, we run this final model with an NB1 specification. The results can be seen in Table 5. The only difference found is that Code 2 is not significant. Nonetheless, if we take into account the Akaike information criteria (AIC), the NB2 model, as expected, adjusts better to our data.

Table 5: Negative Binomial Regression Results $(p=1)$

\begin{tabular}{lcccc} 
& Coefficient & Standard Deviation & $z$ & p-value \\
\hline \hline Constant & -1.44833 & 0.409263 & -3.539 & 0.0004 \\
Weight & 0.01233238 & 0.00431164 & 2.858 & 0.0043 \\
Code 1 & 0.446600 & 0.164477 & 2.715 & 0.0066 \\
Code 2 & -0.481741 & 0.318358 & -1.513 & 0.1302 \\
$\alpha$ & 0.429182 & 0.156938 & 2.735 & 0.0062 \\
\hline Observations & 310 & & & \\
AIC criteria & 738.7830 & & & \\
\multicolumn{4}{r}{ Note: Quasi-Maximum Likelihood Standard Errors. }
\end{tabular}

In Table 8 at the end of Appendix 3, we report other specifications where we control the results of being a second born boy with an older brother (Code 1) and being a second born boy with an older sister (Code 2) with the number of siblings. This last variable is not significant while Code 1 remains as significant as in our previous analyses. In turn, Code 2 loses significance.

We also tested two different specifications capturing more specific data on birth order. On one hand, we introduce a variable Brothers3+, indicating whether a player is or not born after the second brother. The second specification incorporates eight dummies (collectively denotes DummiesBrothers), indicating the specific position in the birth order of a player that is not first born. Both variables are not significant. ${ }^{15}$

Finally, there exists the possibility that being the second born boy with and older brother may be correlated with Weight, according to the findings of Meller et al. (2018), who find that birth order has also an impact on the health of second brothers. We run thus a Hausman test of endogeneity, instrumenting

\footnotetext{
${ }^{15}$ This result is interesting in the light of the possible explanation for the higher tendency to risk taking by second born brothers introduced by Sulloway and Zweigenhaft (2010), namely the effect of a regression to the mean. That is, that second brothers with lesser athletic skills than their older brothers, trying to live up to the expectation that they are at a par with them, take more risks. In our case, if this were indeed so, younger brothers should also exhibit more yellow cards than their older brother. The lack of significance of Brothers $3+$ shows that this is not the case.
} 
Weight with Height. The latter variable is chosen as instrument since its correlation coefficient with Weight is 0.44565732 , which allows to reject the null hypothesis of no correlation $(t(308)=8.73684$, with a two tails $p$-value of 0.0000$)$. Then, the Hausman test yields $\chi^{2}=0.02$, and thus the null hypothesis of exogeneity cannot be rejected, validating the results reported in table 4 .

\section{Conclusions}

In this work we established a significant relation between birth order, the sex of siblings and the behavior in a contact sport (rugby) in a socially and culturally homogeneous setting. Second born boys with older brothers tend to receive more yellow cards than boys with older sisters or ones that are not second born. This result is consistent with the findings of Breining et al. (2020).

While our analysis is not aimed to check which mechanism may explain the observations, our evidence indicates that an alternative explanation of the close association between being the second male child and a certain form of unruly behavior does not yield significant results with our data. Namely, the possibility of a "regression to the mean" effect, conjectured in Sulloway and Zweigenhaft (2010), seems to not be at play in the setting analyzed here. Nevertheless, the fact that we are only considering the performance of amateur players in a single year may in a certain sense obscure the impact of a regression to the mean.

Be as it may, our results might be relevant for designing new policies in sports training. Coaches of child and junior teams should put more attention to the behavior of second born players, being alert to possible misbehaviors and helping them to learn how to control themselves.

A secondary result is the existence of a positive impact of weight on the number of yellow cards. This might be a consequence of the fact that heavy players usually play as forwards, who are more involved in breakdowns, where most of the offenses are committed.

\section{Compliance with Ethical Standards}

Conflict of Interest The authors declare that they have no conflict of interest.

\section{References}

- Adler, A., (1928). Characteristics of the first, second, and third child. Children 3(5): 14. 
- Bard, D.E. and Rodgers, J.L. (2003). Sibling Influence on Smoking Behavior: A Within-Family Look at Explanations for a Birth-Order Effect. Journal of Applied Social Psychology 33: 1773-1795.

- Barclay, K. and Kolk, M. (2018). Birth intervals and health in adulthood: a comparison of siblings using Swedish register data. Demography 55(3): 929-955.

- Bautista Branz, J. (2016). Being close to Europe. Sport, social class and prestige in Argentina. Revista Reflexiones 95(1): 131-142.

- Becker, G. S. (1960). An Economic Analysis of Fertility, Demographic and economic change in developed countries: a conference of the Universities. National Bureau Commitee for Economic Research 209.

- Becker, G. S., and Lewis, H. G. (1973). On the Interaction between the Quantity and Quality of Children. Journal of political Economy 81(2, Part 2): S279-S288.

- Becker, G. S., and Tomes, N. (1976). Child endowments and the quantity and quality of children. Journal of political Economy 84(4, Part 2): S143-S162.

- Black, S. E., Grönqvist, E. and Öckert, B. (2018). Born to lead? The effect of birth order on noncognitive abilities. Review of Economics and Statistics 100(2): 274-286.

- Breining, S., Doyle, J., Figlio, D.N., Karbownik, K. and Roth, J., 2020. Birth order and delinquency: Evidence from Denmark and Florida. Journal of Labor Economics 38(1): 95-142.

- Cameron, A.C. and P.K. Trivedi (2013). Regression analysis of count data. Cambridge University Press.

- Daly, M., and Wilson, M. (1988). Foundations of human behavior. Homicide. Aldine de Gruyter.

- Damian, R. and Roberts, B. W. (2015a). The associations of birth order with personality and intelligence in a representative sample of US high school students. Journal of Research in Personality 58: $96-105$.

- Damian, R. I., and Roberts, B. W. (2015b). Settling the debate on birth order and personality. Proceedings of the National Academy of Sciences 112(46): 14119-14120.

- Dunn, J. and Plomin, R. (1990). Separate lives: Why siblings are so different. Basic Books.

- Ernst, C. and Angst, J. (1983). Birth order: Its influence on personality. Springer-Verlag.

- Esposito, L., Kumar, S. M. and Villaseñor, A. (2020). The importance of being earliest: birth order and educational outcomes along the socioeconomic ladder in Mexico. Journal of Population Economics, DOI : 10.1007/s00148-019-00764-3. 
- Forer, L. K. (1977). The birth order factor. Pocket Books.

- Hertwig, R., Davis, J. N., and Sulloway, F. J. (2002). Parental investment: how an equity motive can produce inequality. Psychological bulletin 128(5): 728 .

- Hilbe, J.M. (2011). Negative Binomial Regression. Cambridge University Press.

- Hotz, V. J., and Pantano, J. (2015).Strategic parenting, birth order, and school performance. Journal of population economics 28(4): 911-936.

- Howarth, E. (1980). Birth order, family structure and personality variables. Journal of Personality Assessment 44(3): 299-301.

- Meller, F. O., Loret de Mola, C., Assunção, M. C. F., Schäfer, A. A., Dahly, D. L. and Barros, F. C. (2018). Birth order and number of siblings and their association with overweight and obesity: a systematic review and meta-analysis. Nutrition Reviews 76(2): 117-124.

- Miguel, E., Saiegh, S. M., and Satyanath, S. (2008). National cultures and soccer violence (No. w13968).National Bureau of Economic Research.

- Nisbett, R. E. (1968). Birth order and participation in dangerous sports. Journal of personality and social psychology $8(4 \mathrm{p} 1): 351$.

- Okudaira, H., Kinari, Y., Mizutani, N., Ohtake, F., and Kawaguchi, A. (2015). Older sisters and younger brothers: The impact of siblings on preference for competition. Personality and Individual Differences 82: 81-89.

- Orme, J. G., and Combs-Orme, T. (2009). Multiple regression with discrete dependent variables. Oxford University Press.

- Puffer, R. R., and Serrano, C. V. (1973). Patterns of mortality in childhood; report of the InterAmerican Investigation of Mortality in Childhood. In PAHO. Scientific Publication (No. 262). Pan American Health Organization.

- Rohrer, J. M., Egloff, B., and Schmukle, S. C. (2015). Examining the effects of birth order on personality. Proceedings of the National Academy of Sciences 112(46), 14224-14229.

- Romand, P. and Pantaléon, N. (2007). A qualitative study of rugby coaches' opinions about the display of moral character. The Sport Psychologist 21(1), 58-77.

- Salmon, C.A. and Daly, M., 1998. Birth order and familial sentiment: Middleborns are different. Evolution and Human Behavior 19(5): 299-312. 
- Sulloway, F. J. (1996). Born to rebel: Birth order, family dynamics, and creative lives. Pantheon Books.

- Sulloway, F. J. (2007). Birth order and intelligence. Science 316(5832): 1711-1712

- Sulloway, F. J., and Zweigenhaft, R. L. (2010). Birth order and risk taking in athletics: A metaanalysis and study of major league baseball.Personality and Social Psychology Review 14(4): 402416.

- Theroux, N. L. (1993). Birth order and its relationship to academic achievement and selected personal traits. University of California.

- Wang, X.T., Kruger, D.J. and Wilke, A., 2009. Life history variables and risk-taking propensity. Evolution and Human Behavior 30(2): .77-84. 


\section{Appendix 1: Survey on family structure of rugby players.}

- First and Last Name

- Age

- Club

- How many years have you been playing rugby? (if you started this year write 0)

- Educational Attainment

- Incomplete Secondary Studies

- Complete Secondary Studies

- Incomplete College Studies

- Complete College studies

- How many siblings do you have?

- Enumerate your and your siblings order of birth, indicating gender, from the oldest to the youngest? (In the positions corresponding to you, write Me). For example: 1.Brother 2. Me 3. Sister 


\section{Appendix 2: Email questionnaire}

In the email questionnaire, the South Rugby Union President was required to put an $\mathrm{X}$ next to the answers he picked. ${ }^{16}$

- Rugby in the URS is:

- Amateur X

- Professional

- How do you consider the competence level in the URS?

- Very high

- High

- Medium X

- Low

- Very low

- How much do you agree with the following statements?:

- Everyone older than 18 years old can find a rugby team in the URS, no matter its skills.

* Really agree $\mathbf{X}$

* Agree

* Do not agree

- Player in the URS, generally shares several cultural characteristics.

* Really agree $\mathbf{X}$

* Agree

* Do not agree

- The URS teams have an homogeneous social and economic level..

* Really agree

* Agree X

* Do not agree

In the email questionnaire, the South Rugby Union Referee Manager was required to put an $\mathrm{X}$ next to the answers he picked. ${ }^{17}$

\footnotetext{
${ }^{16}$ Contact: martonazpiroz@gmail.com

${ }^{17}$ Contact: marjoa08@gmail.com
} 
- How much do you agree with the following statements?:

- Junior rugby referees are usually new referees.

* Really agree

* Agree X

* Do not agree

- Junior rugby referees prefer to be more pedagogical and show less yellow cards that are usually shown in a seniors game.

* Really agree

* Agree X

* Do not agree 
Appendix 3: Regression Results 


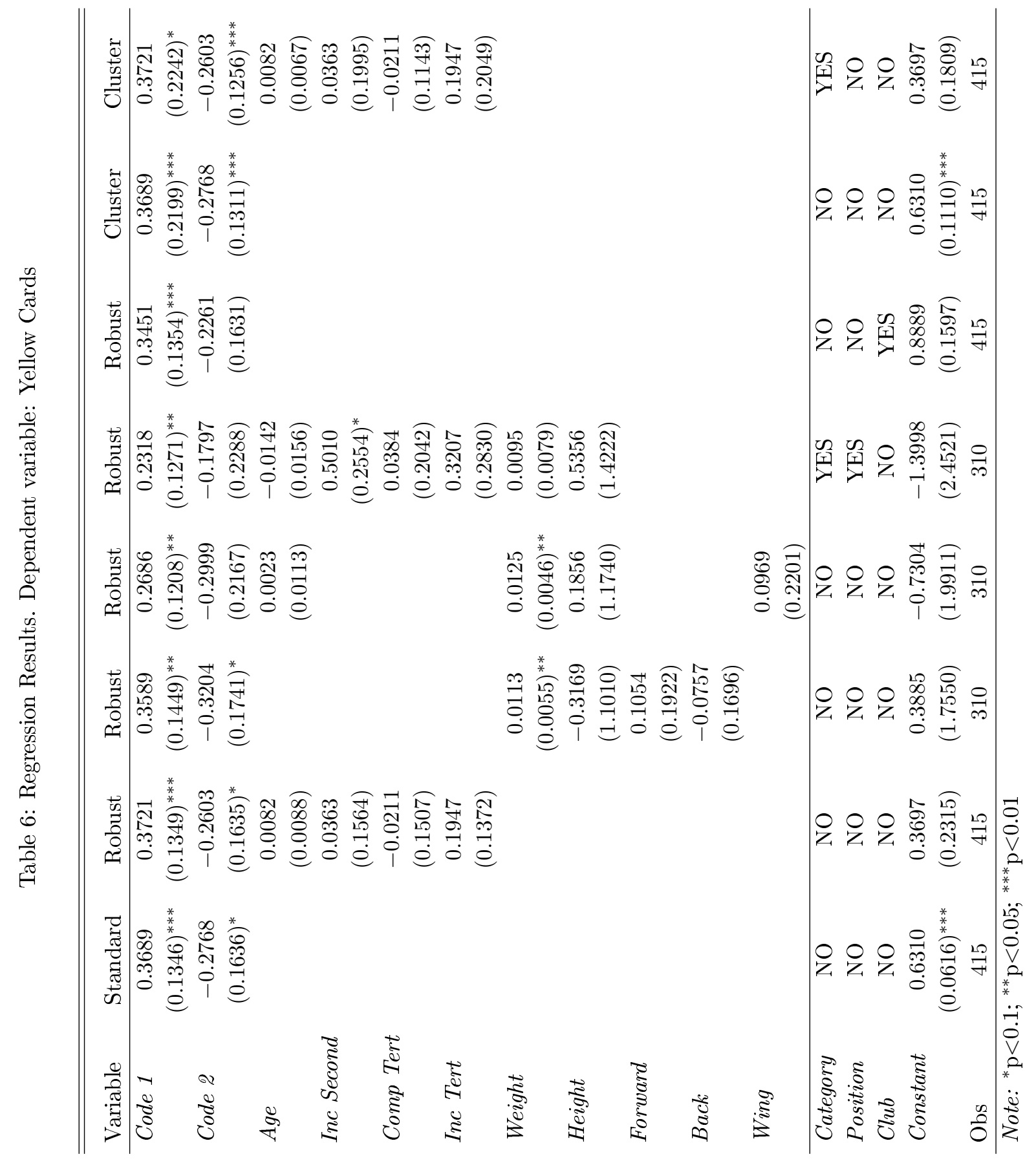




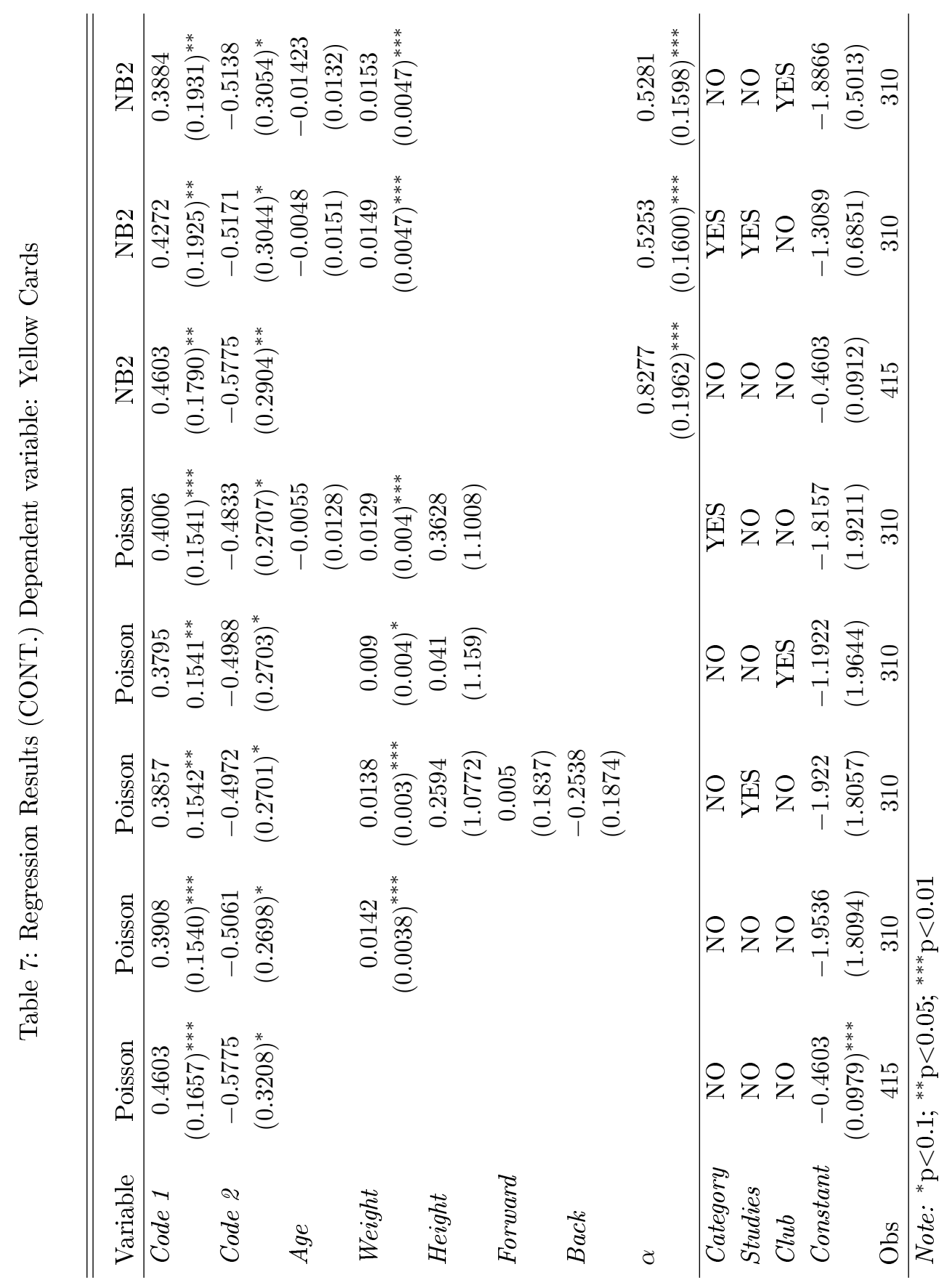




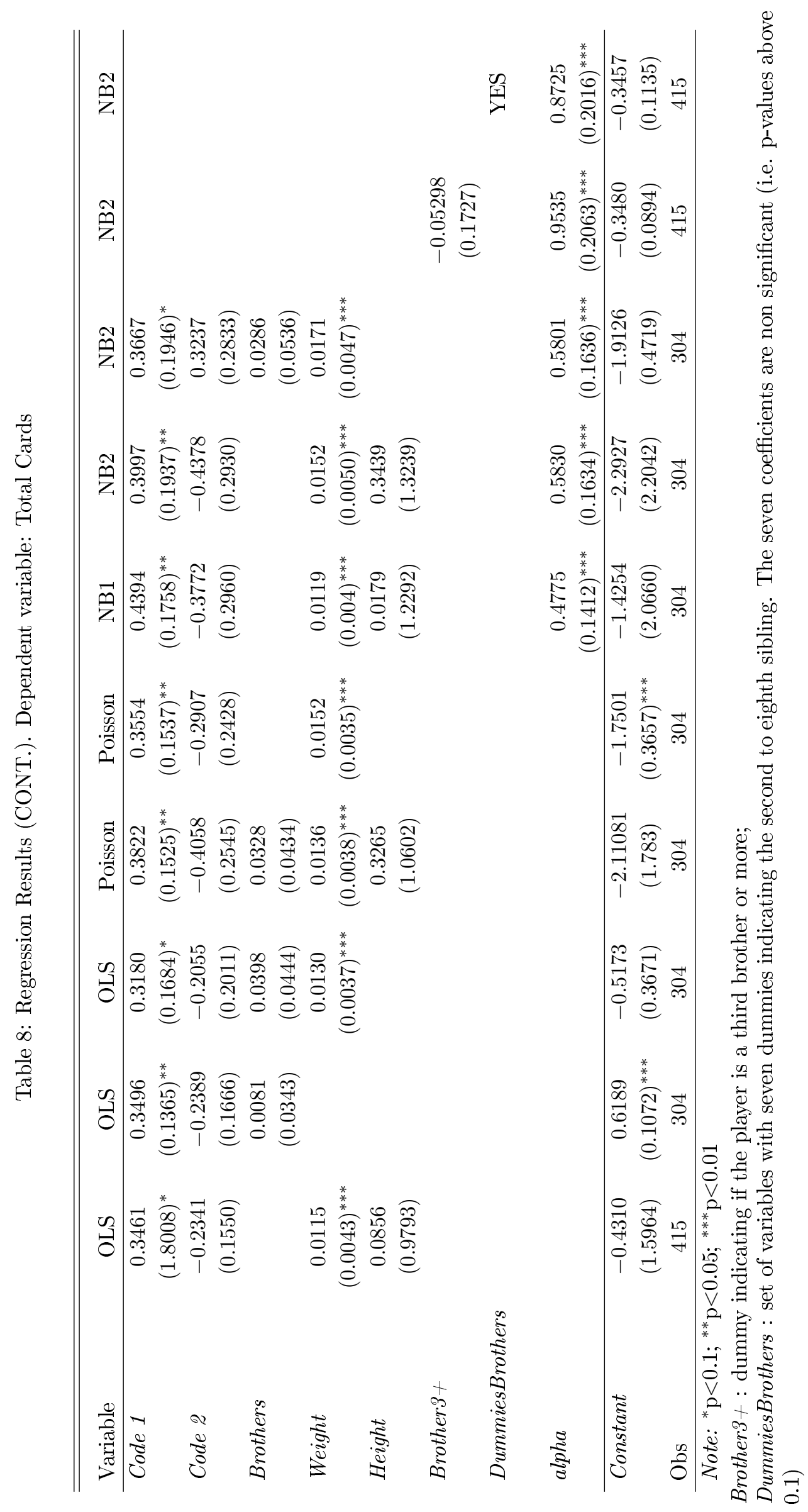

